\title{
A diagnostic score for ischemic colitis in the elderly
}

\author{
M Mosele ${ }^{1 *}$, E M Inelmen ${ }^{1}$, F Cardin ${ }^{3}$, P De Carlo ${ }^{1}$, S Fratta ${ }^{1}$, E Perissinotto ${ }^{2}$, C Terranova $^{4}$, E Manzato $^{1}$ \\ From de Senectute: Age and Health Forum \\ Catanzaro, Italy. 5-7 December 2009
}

\section{Background}

Ischemic colitis (IC) is the most common form of ischemic injury of the gastrointestinal tract and mortality is still high [1]. Although prompt suspicion and exact diagnosis, especially in elderly people, are highly critical, there have been few reports on risk factors for presumed IC compared with the general elderly population [2]. We performed this study to create a diagnostic score for IC in the elderly .

\section{Materials and methods}

A retrospective study was undertaken on 78 patients with IC admitted to Padova General Hospital between 2003 and 2008. Only patients with biopsy-proven IC were considered. Seventy eight control subjects were randomly selected from those seen at our units for acute geriatric disease during the same interval. IC risk factors resulted significative by univariate analysis, were put in a stepwise logistic regression model. In order to evaluate the adequacy of the model in the correct classification of the patients on the basis of their clinical condition, the Hosmer and Lemeshow test (Goodness-of-Fit Test) was applied. The score for every single variable introduced in the model was also evaulated the global score for every subject put in the study was calculated. Finally in order to identify the best cut off of the global score to discriminate between "positive" and "negative" subjects in the IC diagnosis, a ROC analysis was performed. The area under the curve (AUC) was used as an accuracy index of the model

\section{Results}

The risk factors for IC identified at univariate analysis were analyzed in a stepwise regression logistic model and 5 of them confirmed their independent significance
Table 1 Predictors of ischemic colitis, regression coefficient and single calculated score

\begin{tabular}{lcll}
\hline & $\beta^{*}$ & $\mathrm{P}$ & Score \\
\hline Hematochezia & 4.04 & $<0.0001$ & 0.48 \\
Vasculopathy & 2.23 & 0.0002 & 0.24 \\
Cancer & 1.77 & 0.0018 & 0.18 \\
Creatinine & 1.54 & 0.0016 & 0.16 \\
Heart disease & 1.1 & 0.0251 & 0.12 \\
\hline
\end{tabular}

* regression coefficient

as risk factors (Tab.1). For every predictive variable for IC, regression coefficient and the corresponding score were considered (table 1). ROC analysis, finally, identified as cut off point the value of 0.72 for the global score (Specificity=90,3; Sensibility=74,3) AUC resulted 0.834 , index of a moderate accuracy of the model.

\section{Conclusions}

Despite the small number of patients included in this study, our diagnostic model of IC in the elderly shows a moderate accuracy. The discriminating cut off point on the possible diagnosis of IC, even if endowed with minor sensitivity and specificity compared to instrumental examinations, is easily and rapidly applicable to every single patient, particularly to the elderly.

\section{Author details}

'Department of Medical and Surgical Sciences, Division of Geriatrics, University of Padua, Italy. ${ }^{2}$ Department of Environmental Medicine and Public Health, University of Padua, Italy. ${ }^{3}$ Geriatric Department, Division of Geriatric Surgery, University of Padua, Italy. ${ }^{4}$ Toxicology and Antidoping Hospital University of Padua, Italy.

Published: 19 May 2010 


\section{References}

1. Huguier M, Barrier A, Boelle P Y, Houry S, Lacaine F: Ischemic colitis. The American Journal of Surgery 2006, 192:679-684.

2. Chang L, Khaler KH, Sarawate C, Quimbo R, Kralstein J: Assesment of potential risk factors associated with ischaemic colitis. Neurogastroenterol Motil 2008, 20(z):36-42.

doi:10.1186/1471-2318-10-S1-A18

Cite this article as: Mosele et al:: A diagnostic score for ischemic colitis

in the elderly. BMC Geriatrics 2010 10(Suppl 1):A18.

Submit your next manuscript to BioMed Central and take full advantage of:

- Convenient online submission

- Thorough peer review

- No space constraints or color figure charges

- Immediate publication on acceptance

- Inclusion in PubMed, CAS, Scopus and Google Scholar

- Research which is freely available for redistribution

Submit your manuscript at www.biomedcentral.com/submit
C Biomed Central 